\title{
A Study of Sports Facilities in the Colleges of Nashik City
}

\author{
Dilip N Londhe, \\ RNC Arts, JDB Commerce and NSC Science College Nashik Road 422101
}

\begin{abstract}
The aim of this paper is to study sports facilities and its impact in the colleges of Nashik city. We collect the data from various colleges of Nashik city and analyze. We apply a survey method to analyze the data. The analysis of the data is represented graphically because it is easy to evaluate the sports facilities (indoor and outdoor) available.
\end{abstract}

Also, we recommended some remarks in the improvement for better facilities to provide the students. Keywords: Sports Infrastructure, Indoor Facility, Outdoor Facility, Government Grants Students.

\section{Introduction}

In the last couple of decades, sports activities have been gaining a great momentum in India. Although cricket is the most passionately in India, other sports like football, hockey, volleyball, basketball, badminton, kabbadi, kho-kho and table tennis too are popular among the youth today. The performance of India in the Olympics has always been a pathetic one. One of the major reasons is the poor encouragement of sports at the school and college levels. The lack of facilities is a major detrimental factor in the development of sports culture in the colleges. In the recent years, Nashik has seen a slight increase in sporting activities. This can be largely attributed to the success of the local athletes Monica Athare and Kavita Raut at the national and international levels. The situation however in the colleges remains a cause for concern. Sports and sports facilities take a back seat when it comes to budgetary provision in majority of the higher academic institutions. The present study is an attempt to review the status of the sports facility in the colleges of Nashik district. Only those colleges within the Nashik Municipal area were included in the study. A total of 10 aided colleges, 11 unaided colleges and 12 professional colleges were surveyed for the study. The colleges were surveyed for their indoor and outdoor facility, availability of Physical directors, coaches etc. It was found that the colleges lacked standard physical infrastructure required to groom sportspersons. Professional and unaided colleges don't have qualified fulltime physical director. The study presents a comparative review of the sports infrastructure of the colleges. Recommendations and suggestions are provided to improve the condition of the sporting culture of colleges. In the next section, we review some research papers, which are useful for further development of our study.

\section{Review of Literature}

Bogar (2012) studied the trends in the construction and design of recreational sports facilities in the colleges in the U.S. He observed that many new and renovated facilities have integrated important campus functions such as academics, health, wellness, and sport. These recreational sports facilities also contain unique features such as climbing walls, rooftop playing fields, food service, counseling centers, convenience stores, and campus police stations.

Robert (2012) carried out a research on the impact of Campus Recreational Sports Facilities and Programs on Recruitment and Retention among African American Students. The study aimed to assess the impact of campus recreational sports facilities and programs on student recruitment and retention among male and female African American students. It was determined that $60 \%$ of the male students reported that the availability of recreational sports was important/very important in deciding to attend the college and $68 \%$ of the men reported that the availability of recreational sports was important/very important in deciding to continue attending the college. Men scored higher than women when it came to importance of the availability of recreational facilities and programs in deciding to attend the school, the importance of the availability of recreational facilities and programs in deciding to continue at the school, how important sports and fitness activities will be to them after graduation, and the total times per week they participate in active recreational sports pursuits.

Antón (2011) carried out a study titled "How construction trends of Universities sport facilities will be affected by financial crisis". The results showed that a high percentage of the respondents agreed the use, construction and renewal of sport facilities in Spanish Universities would continue increasing for the next three years. They observed that with respect to the architectural trends, the wellness and recreational centres would be more successful than other options such as climbing walls or centres integrating sports and arts. They further observed that these trends are more affected by cultural and social factors than by the economy. 
Zhou (2010) studied the relationship between College Sports Facilities and Mass Sports. He feels that industrialization of college sports facilities is a crucial problem that should be solved in Post-Olympic Era. He further suggests that college sports facilities should be open to the public to solve the following problems: to relieve the scarcity of sports facilities; to favor the development on mass sports; to be aware of the characteristic of college sports resources; to clear the relationship between the college sports resources and the development on mass sports; to strengthen the awareness on establishment of the society with its resources shared by the public; to service the public with the abundant resources in college; to establish a new cultural community of the public and the colleg

Barghchi (2010) conducted a research study on sports facilities construction in Malaysia. They observed that sports and sports facilities development have improved rapidly over the past years in Malaysia but feel that such improvement is inadequate compared to the overall development of sports at international level. Their study used the expert opinions of town planners, as key players in decision making in the Malaysian context. The findings from the research revealed that although, in Ninth Malaysia Plan (2006-2010) emphasis is placed on creating a sports culture among Malaysian, sports facilities have not gained new role as the global trends, yet. The researchers feel that there is still a need for a new perspective and a new approach to improve the existing sports facilities and for future development.

Arslan (2010) conducted a research for recommendations to improve sports facilities in the University. He found that there were very little sports facilities in the University. There was a lack of proper sports facilities, well trained coaches, separate place for female sports and sports budget etc.

Feng and Humphreys (2008) in their study examined the economic impact on residential housing values. Their results show that sports facilities have a "significant positive effect on the value of surrounding houses and this positive effect decreases as the distance from the facilities increases. They further add that a new sports facility constructed in the core of a large city as part of an urban redevelopment program might possibly cause residential property values within one mile of the facility to increase hundreds of millions of dollars. A new sports facility constructed outside of the center of a large city and unrelated to an urban redevelopment program will cause residential property values around the facility to increase tens of millions of dollars. According to them this might help to explain why cities continue to subsidize sports facilities even when much academic research suggests that they result in little or no tangible economic benefits.

\section{Objective of the study}

The objective of the study is to examine the existing sports facility in the senior aided, non aided and professional colleges of Nashik city.

\section{Methodology of the study}

The study included 10 aided colleges, 11 unaided colleges and 12 professional colleges. Data was collected from the affiliated colleges of Pune University in Nashik district, with the help of questionnaire prepared in consultation with existing sports field authorities

\subsection{Indoor Facility}

\section{Results and discussions}

Only $60 \%$ percent of the aided colleges surveyed had indoor facility. Out of 11 unaided colleges that were surveyed only $27 \%$ of them had indoor facilities while $73 \%$ did not. The condition of the professional colleges was even worse. Out of the 12 colleges surveyed, only 2 colleges i.e 17 percent had indoor facilities.

Chart 1. Graphical representation indoor facility of colleges

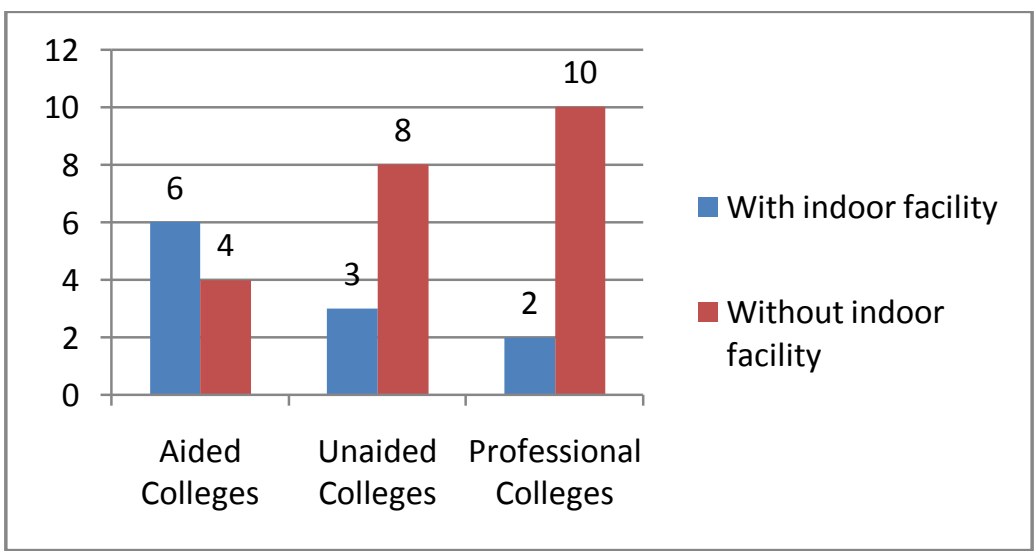




\subsection{Outdoor Facility}

Out of the 10 aided colleges surveyed, 7 of them i.e. $70 \%$ had outdoor facility. Out of the 11 unaided colleges, 6 of them i.e. nearly $55 \%$ of them didn't have any outdoor facility and only $45 \%$ had outdoor facility. The situation of the professional colleges surveyed was slightly better. $58 \%$ of the professional colleges had outdoor sports facility.

\section{Chart 2. Graphical representation outdoor facility of colleges}

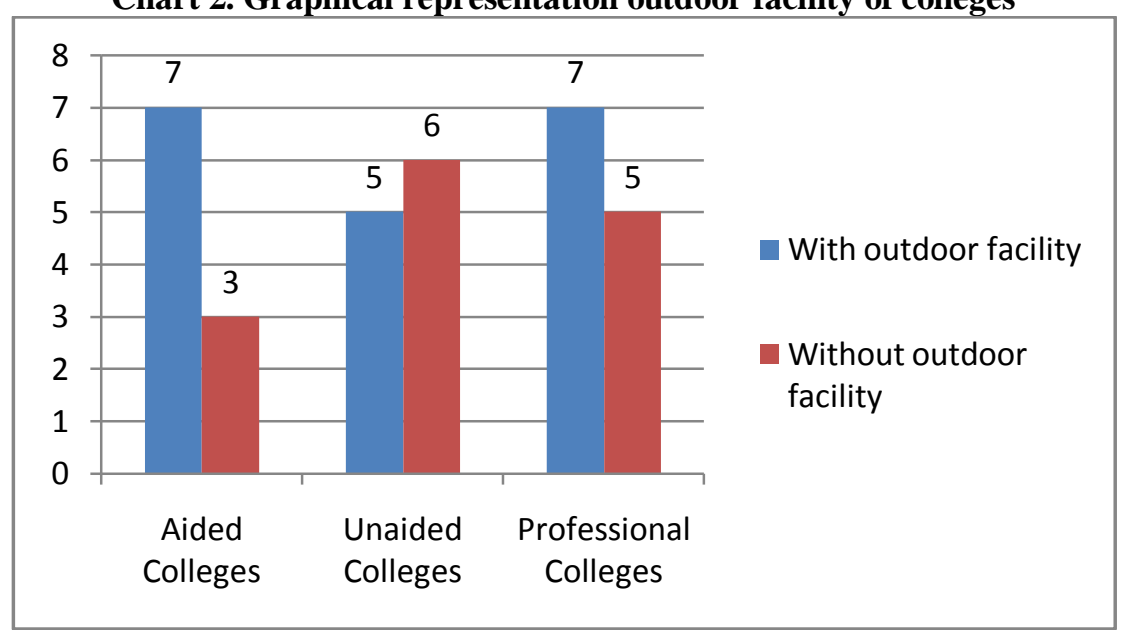

There is ample scope for development of sports facilities in the colleges in Nashik city. The dearth of facility is felt during competitions especially inter-college or zonal competitions. Some of the colleges had common sports facilities which they shared with their sister concerns or the institutes run under the auspices of their parent organization.

\subsection{Availability of Qualified staff}

Recruiting a full time qualified staff makes a colossal difference in providing training to students. During the survey it was found that all of the aided colleges had qualified and fulltime Physical Directors. Only 6 colleges i.e $55 \%$ had Physical Directors. But they were not qualified staff and were not paid as per norms. In professional colleges the condition was even worse. Only 3 professional colleges i.e. $25 \%$ had recruited physical directors.

\section{Chart 3. Graphical representation of availability of Physical Directors}

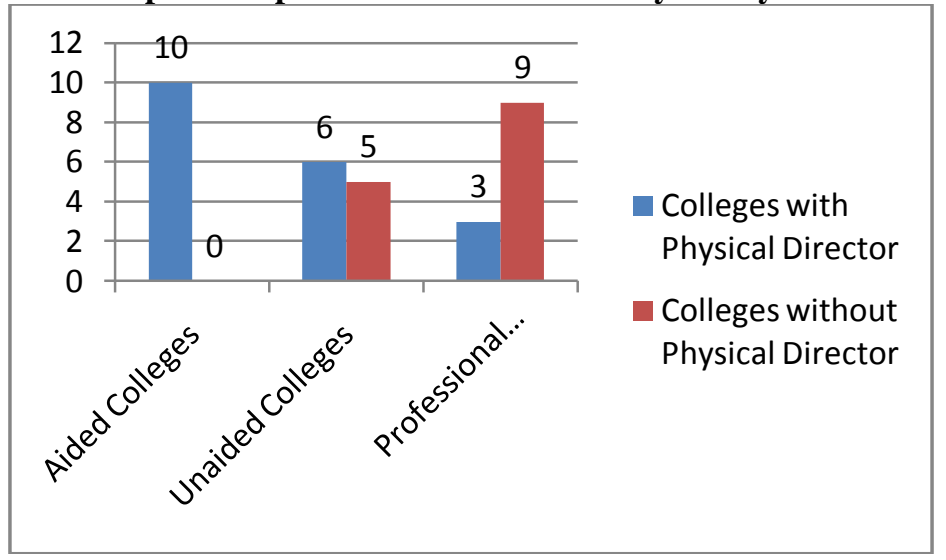

\subsection{Recommendations}

Nashik has a great potential to produce competent sportspersons and as stated earlier, Kavita Raut and Monica Athare hail from Nashik and have made their marks in international circuits. Nashik needs to capitalize on the achievements of these athletes and motivate students to involve in sporting activities. College authorities should provide the impetus by creating standard sports infrastructure. To improve the overall conditions of sports infrastructure in the colleges, the authorities should make optimum use of the grants provided by the Govt. and universities. 
Following are some of the recommendations for improving the sports facilities and enhancing overall sporting culture of the colleges

1. Colleges should appoint a full time Physical Director who apart from fulfilling the minimum eligibility qualifications should also be a sportsperson of repute.

2. In addition, colleges may also look sports consultants who have represented India in Olympics, Asian games or Commonwealth. This would not only motivate the students but will also help to bring in professionalism and enhance sporting culture in the campus.

3. College Management should create sufficient funds in the form of grants or alternative means to invest into creation of good indoor and outdoor facilities.

4. Excellent sports infrastructure should be promoted so as to attract maximum students towards enrollment in the respective colleges

5. Students who participate in sports competitions should be paid TA/DA and also should be provided with proper sports kits.

6. Students who participate in the district, state and national level matches should be honored and given encouragement in the form of some monetary awards, certificates and some privileges.

India is second most populous country in the world but its performance in Olympics is well below small countries like Japan, Kenya, U.K etc. Sports in colleges need to be given priority by the management. Funds should be optimally utilized to create good indoor and outdoor facilities. Periodic assessments may be carried out to by the management or external body to justify the investments if necessary. Colleges should also ponder on the possibility of mandatorily including sports in the curriculum.

\section{References}

[1]. Antonio, J. Monroy, Antón (2011). How construction trends of Universities sport facilities will be affected by financial crisis: A survey. Scientific Research and Essays. 6(9), 1998-2002.

[2]. Arslan, Dilawar (2010). Research information and recommendations to improve sports facilities in university. Thesis report submitted to the Superior University Lahore.

[3]. Bargchi, Massoumeh et al. (2010). Exploratory research on sports facilities construction in Malaysia. Australian journal of basic and applied sciences. $4(10): 5326-5331$

[4]. Bogar, Craig. T. (2012). Trends in Collegiate Recreational Sports Facilities. The sport Journal. Pp.15.

[5]. Dabas, Chandra, Sarkar (1982). The Survey of Facilities and Equipments of Sports in Engineering Colleges in West Bengal Unpublished Master's Thesis, Laxmibai National Institute of Physical Education, Jiwaji University, Gwalior.

[6]. Feng X. and Humphreys, B. R. (2008). Assessing the Economic Impact of Sports Facilities on Residential Property Values: A Spatial Hedonic Approach. North American Association of Sports Economists working paper series 08-12.

[7]. Hui, Zhou. (2010). Research on relationship between College Sports Facilities and Mass Sports. The Conference on Web Based Business Management.(pp. 425-428). Chengdu. Scientific Research Publication.

[8]. Robert, Lindsey (2012). Impact of Campus Recreational Sports Facilities and Programs on Recruitment and Retention Among African American Students: A Pilot Study. Recreational Sports Journal,33(1). 25-34. 